\title{
The Profound of Students' Supervision Practice in Higher Education to Enhance Student Development
}

\author{
Affero Ismail ${ }^{1}$, Norhasni Zainal Abiddin ${ }^{2}$, Razali Hassan ${ }^{1}, \&$ Ihsan Ro'is ${ }^{3}$ \\ ${ }^{1}$ Faculty of Technical and Vocational Education, Universiti Tun Hussein Onn Malaysia, Malaysia \\ ${ }^{2}$ Faculty of Educational Studies, Universiti Putra Malaysia, Malaysia \\ ${ }^{3}$ Faculty of Economic Studies, Universitas Maratam Indonesia, Indonesia \\ Correspondence: Associate Professor Dr. Norhasni Zainal Abiddin, Department of Professional Development \\ and Continuing Education, Faculty of Educational Studies, Universiti Putra Malaysia, 43400 UPM Serdang, \\ Selangor, Malaysia. Tel: 603-8946-8240. E-mail: nonie@upm.edu.my
}

Received: March 28, 2014 Accepted: June 21, 2014 Online Published: July 29, 2014

doi:10.5539/hes.v4n4p1 URL: http://dx.doi.org/10.5539/hes.v4n4p1

\begin{abstract}
Supervision has become a highlight in higher education in recent years. While striving for the quality of education, the stress in research supervision has become dominant. Excellent research can contribute to the prominent of institutions' image. This paper accumulates the models from expert scholars in students' development regarding supervision issue. The models have their own functions and strengths. This can be proved by revising at the thorough implementation. Most supervision approaches and models have mutual aptitude: (1) The relationship establishment that was built on good communication, expectation and confidentiality; (2)The formulation of student-based, agreed upon aims and outputs; and (3)A systematic training and learning process in relation to the goals. This paper will discuss appropriate models that can be studied in student development.
\end{abstract}

Keywords: student development, supervision, supervision model, quality education

\section{Introduction}

Educating early stage of young researchers is a complex effort. This means that their skills will become ever more crucial. This is important to increase the amount of innovative research. The supervisors have an important role to play in this matter. Here, it is discussed that the research outcome was affected by the supervisor's conception of supervision skill. Models of supervision including learning process during students' progress will be highlighted and introduced. The problems and challenges that confront the students are often similar. Proper guideline and collaboration with their supervisor are at utmost important. Any supervisory process needs to acknowledge the differences between student-supervisors' roles to enhance research skills. This paper aims to guide the supervisors in maintaining a balance between these demands. The supervisor must develop themselves with core skills in research supervision and providing essential input for student development. The objective of this paper is to discuss the models and practice of students' supervision. The methodology used to accumulate the contents in this paper was through analysis and thorough reading from reports, papers, journals and articles by previous authors and researchers.

Supervision is an inter-relational process, including interior and exterior factors as well as individual that occur between student and supervisor. The bond that develops between them depends on how well they manage their relationship (Abiddin, 2006, 2007). Most of the supervision activity must be supported with supervisors' input (Abiddin \& West, 2007). There are series of tasks and responsibilities that should be taken into account. How a supervisor works depends on the range and depth of supervision concept that he/she possessed. The supervisor should maintain the conducive atmosphere for creativity and productivity, and to provide mechanisms for resolving problems which may arise between them (Ismail \& Abiddin, 2009). Thus, the skills of effective supervisor are utmost important. 


\section{Objective and Methodology}

Students from previously disadvantaged backgrounds may have further distinctive needs in order for them to make out with the pressures of a technologically advanced environment and a system that demands independent research (Lessing \& Schulze, 2002). Furthermore, Lessing and Lessing (2004) adds the following general aspects that influence graduate completion rate: student-friendly, accessible administrative procedures, understanding academic and scientific requirements, ability to judge workload related to different parts of the inquiry process, retaining supervisor contact, overcoming isolation, conflict management, and the power to bring a stand and argue a view in terms of the study. Thus, they need support from the institution and the supervisor to keep them continuing their studies. In this case, models of effective supervision are very crucial to be studied. This article explains the important related models to be practiced in supervision. A collective of theory and model were analyzed accordingly to come out with an effective supervision practice.

\section{Qualities Model}

There is always a demand for quality in any services or experience. Supervision that perceived by the students also needs to be in good term. The research to determine the qualities of an effective supervisor is not exactly a model in itself, but Wisker et al. (2003) argue that emotional intelligence and flexibility play a big part in working with students through to successful completion. The list of indicators proposed by Zubir-Skerrit and Roche (2004) could be used to identify the effective supervisor. Zuber-Skerritt and Roche (2004) in the finding list out the indicator for effective supervisor where the effective supervisor should have larger experience, encouraging, facilitator of learning, resourceful, directed to student's needs highly organized and supportive while ineefective supervisor might have small experience base, uncertain role, not resourceful, driven by self-needs, lacks of supervision experience and judgemental. A table of function between student and supervisor can provide a useful guideline to speak out their expectations and distributing responsibilities. This is a basic stage for effective and understanding supervision.

\section{A Mentoring Process}

Supervision can be considered as facilitative process that requires supports and challenges (Pearson \& Kayrooz, 2004). This includes providing research tasks and activities such as progress of the students, training and learning, coaching and mentoring, and encouraging student participation. The mentor is seen as a good adviser and not judgmental. The mentor should acknowledge the mentee to grow from dependent to independent and can adapt to change. Schon (1987) explained three justifications in coaching: (1) Joint Experimentation Model where they work closely together; (2) Follow Me where the student follows their supervisor's step; and (3) Hall of Mirrors where the student reflect their session. These justifications normally found together in practice. The roles of a coachee and coach sometimes can shift from one to other. In this coaching session, the coach is male while the coachee is female. The coach is challenged to find appropriate ways to achieve the training objectives.

\section{A Critical Thinking Model}

Critical thinking is a way of deciding the trueness of a claim. Skill of critical thinking is the ability to articulate an issue and anticipation the problems that include the process of observation, interpretation, evaluation, explanation, and also meta-cognition in order to find a solution or alternative to problems. Critical thinking provides skills, knowledge and attitudes that formed as a tool to help student in applying rational thinking, engaging problems and come out with decisions. The model normally works through three steps which are problematizing, finding connections and uncovering conceptions and the shape of an answer.

\section{Experiential Learning Model}

This supervision model is based on a cognitive and self-regulatory approach to learning in a collaborative learning environment, reflecting the constructivism as the underlying theory (Tancig, 2007). The focus of this approach is much more on the learning process than on the teaching process. The goal of the supervising model is to develop subject specific and generic (transferable) competencies (instrumental, interpersonal and systemic).

The first starting point for the supervising model was PBL (Problem Based Learning), which is a strategic answer to development of competencies need in knowledge processing, problem solving, reflective thinking, communication and social interactions-cooperation and collaboration. Learning in our supervising model is thus organized around problems that are relevant for desired competencies, and takes place in an environment that promotes self-regulated learning, critical thinking and self-evaluation. The starting point of the presented supervising model is "learning by doing", a key rationale underlying postgraduate programs and student-centered approach. It means that the starting point for setting up supervision depends to a large extent on learning outcomes and competencies relevant for doctoral study. These competencies emphasize skills of knowledge 
processing, problem solving, creativity, communication, collaboration, etc. The next starting point is the Kolb's cycle-the model of experiential learning consisting of 4 consecutive phases: experience, reflective observation, abstract conceptualization and action.

To fulfill required conditions, we developed a model of supervision based on two learning theories: experiential learning developed by Kolb (1984) and cognitive apprenticeship (Collins et al., 1991). Learning process in supervising model is characterized by problem based learning (PBL) and Kolb's theoretical model of experiential learning. Learning process in this model is organized around problems that are relevant for desired competencies. In an experiential learning structure all four stages have to be involved. According to this model, students develop expertise as they define a problem, search for information and knowledge, learn to see patterns in details, revise schemes in their mental models, and construct and carry out new courses of action.

This cycle can be used for one's orientation. Whenever students are in their learning process they know the next point to which they should go next. This cycle is a very useful tool for the design of experiential learning both in individual and group supervision settings. Learning environment in the presented model of postgraduate supervision is structured according to cognitive apprenticeship, which is focused on four dimensions: content, method, sequencing and sociology. Content refers to different types of knowledge required for expertise. In postgraduate supervision domain knowledge (declarative and procedural) and strategic knowledge (cognitive and metacognitive) are important for the development of appropriate competences. A postgraduate supervisor not only guides knowledge acquisition but equally formation of higher-order cognitive processes, like problem finding and problem solving, metacognitive awareness and self-regulation strategies. Method can be seen as the most powerful dimension of student supervision. In the model emphasis is on methods of articulation, reflection and exploration. The supervisor has to encourage students to articulate their reasoning, problem solving processes, understanding and knowledge, in one to one relation or in cooperative group activities. Reflection involves enabling doctoral students to compare their performance, thought processes and methods with others. Students have to be able to reflect on process in collaborative learning environment. Exploration involves guiding students to survive and solve their own problems. Sequencing of learning activities and tasks is also an important dimension of learning environment. Cognitive apprenticeship provides some principles to guide along this dimension, like increasing intricacy, increasing multiplicity, and focusing on global before local, to be taken into account by a supervisor.

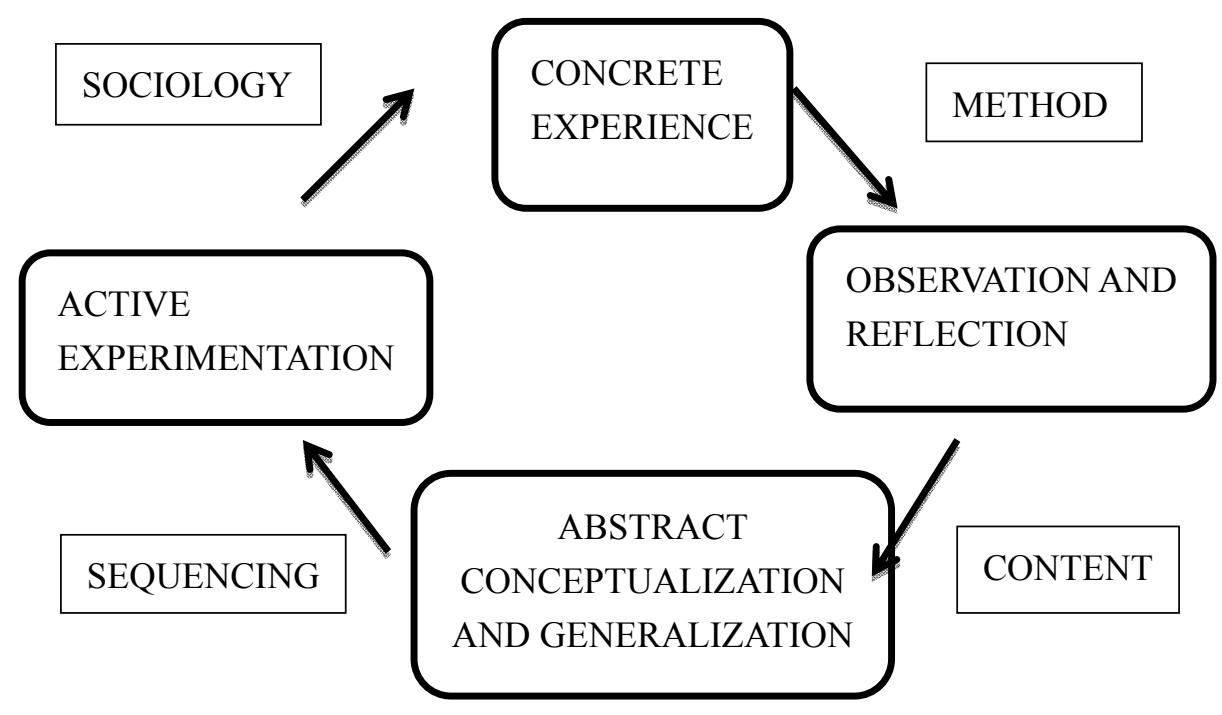

Figure 1. Kolb's four stage cycle of learning process in the framework of four dimensions for designing cognitive apprenticeship environments (Kolb, 1984)

Many scholars proposed that ELT is built on six propositions where: (1) Learning is best considered as a process, not the outcomes; (2) Re-learning is a learning; (3) Learning requires the resolution of conflicts; (4) Learning is an universal process of individual adaptation to the world; (5) Learning results from synergetic transactions between the person and the environment; and (6) Learning is the process of creating experience and knowledge (Kolb \& Kolb, 2005). The primary focus in improving higher education is to engage the students to develop and 
response to their learning efforts. The students will be more confident to voice out their ideas and share their knowledge so that in turn they can be polished and refined with better ideas.

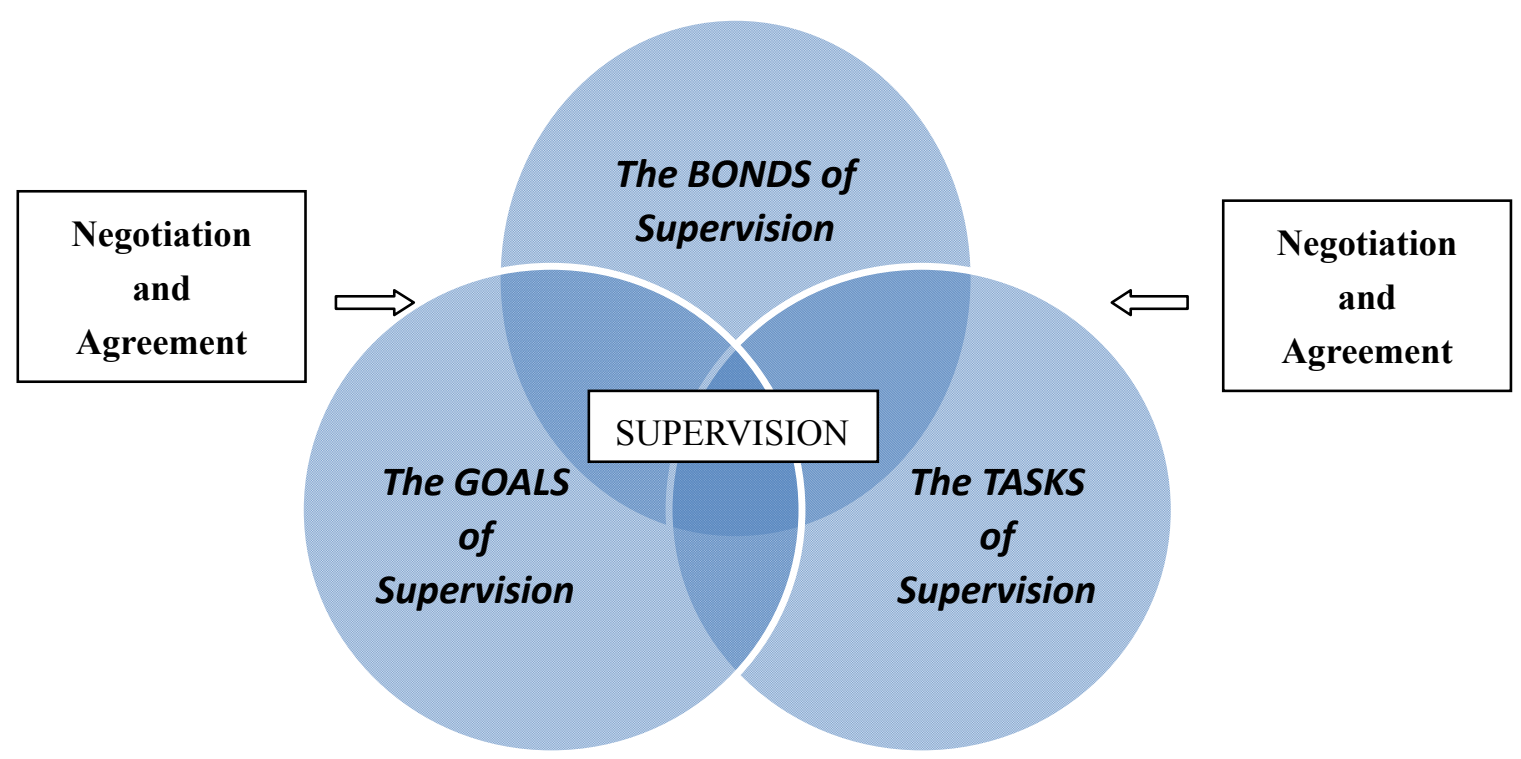

Figure 2. Bordin's working alliance model

\section{Bordin's Supervisory Working Alliance Model}

The Supervisory Working Alliance as proposed by Bordin (1983) stands on three major components: (i) mutual agreement on supervision goals, (ii) specific tasks related to the goals, and (iii) the bonds development between supervisee and supervisor. It was the relational bond that develops between them when they work together. To achieve mutual goals, clear tasks were identified. We can see how far the quality of SWA by the particular characteristic reflective of the how strong the relationship. It will be based on supervisee's perception. In a study by Sterner (2009), the author rated the strength of the relationship by positive as high-quality SWA and negative as low-quality SWA. Positive relationship shows that the relationship is strong.

Table 1. Summary models in supervision

\begin{tabular}{ccc}
\hline Concept Of Supervision & Most Prominent Activity & Knowledge \& Skills Needed \\
\hline Qualities & $\begin{array}{c}\text { Supervising according to } \\
\text { experience } \\
\text { Emancipation }\end{array}$ & $\begin{array}{c}\text { Emotional intelligence; Experience } \\
\text { Mentoring } \\
\text { Critical thinking }\end{array}$ \\
$\begin{array}{c}\text { Experiential Learning } \\
\text { Model }\end{array}$ & Learning through experience & Facilitation \\
SWA Model & Meeting and consultation & Facilitation; Sharing \\
\hline
\end{tabular}

The Supervisory Working Alliance, also known as the working relationship gives impact to the supervision effectiveness. This research will explain more practical, concrete tasks and interaction between student-supervisor relationships in the community setting. The specific components of Bordin's theory expand upon other definitions of the working alliance that consider only the affective relationship or emotional bond between the client and supervisor. Each party understands and agree upon his or her individual duty to perform 
particular assigned tasks and goals, or the mutually agreed upon ideal outcomes of the activity or therapy (Bordin, 1983).

\section{Conclusion}

Five models have been discussed in this paper and all of them focusing on the processes and procedures in students' supervision. They share similar concept from the establishment of a relationship, the formulation of student-based and training and learning in the research process. These models can be practiced and applied accordingly to achieve research target. Moreover, more research on this knowledge can be further explored. The summary of the models discussed in this paper can be studied from Table 1. The concept of supervision might be different but the knowledge and skill needed cannot be ignored to support the supervision activity. Thus, supervisors are encouraged to enhance their skills to improve supervision process.

\section{Acknowledgements}

Special thanks dedicated to the Public Service Department, Government of Malaysia for the sponsorship in this research and highly appreciation to all research partners for the effort in making this research a true success.

\section{References}

Abiddin, N. Z. (2006). Graduate Research Student Policy: A Study of United Kingdom Universities' Practices. European Journal of Social Sciences, 4(2), 127-136.

Abiddin, N. Z., \& West, M. (2007). Supervision Practices for Foreign Graduate Research Student. American Journal of Applied Sciences, 4(6), 362-370. http://dx.doi.org/10.3844/ajassp.2007.362.370

Abiddin, N. Z. (2007). The Role of an Effective Supervisor: Case Studies at University of Manchester, United Kingdom. European Journal of Scientific Research, 16(3), 380-394.

Bordin, E. S. (1983). A working alliance based model of supervision. The Counseling Psychologist, 11, 35-42. http://dx.doi.org/10.1177/0011000083111007

Collins, A., Hawkins, J., \& Carver, S. (1991). A cognitive apprenticeship for disadvantaged students. In B. Means, C. Chelemer \& M.S. Knapp (Eds.): Teaching advanced skills to at-risk students. San Francisco: Yossey-Bass.

Kolb, A. Y., \& Kolb, D. A. (2005). Learning Styles and Learning Spaces: Enhancing Experiential Learning in Higher Education. Academy of Management Learning \& Education, 4(2), $193-212$. http://dx.doi.org/10.5465/AMLE.2005.17268566

Ismail, A. \& Abiddin, N. Z. (2009).The Importance of Graduate Students' Needs on Supervisory Contribution in a Malaysian Public University. The Social Sciences, 4(4), 355-365.

Kolb, D. (1984). Experiential learning. London. Prentice-Hall.

Lessing, A. C., and Schulze, S. (2002). Graduate supervision and academic support: Students' perceptions. South African Journal of Higher Education, 16(2), 139-149. http://dx.doi.org/10.4314/sajhe.v16i2.25253

Lessing, N., \& Lessing, A. C. (2004). The supervision of research for dissertations and theses. Acta Commercil, 4 , 73-89.

Pearson, M., \& Kayrooz, C. (2004). Enabling Critical Reflection on Research Supervisory Practice. International Journal for Academic Development, $\quad 9(1), \quad$ 99-116. http://dx.doi.org/10.1080/1360144042000296107

Schon, D. A. (1987). Educationg the Reflective Practitioner. San Francisco: Jossey-Bass.

Sterner, W. R. (2009). Influence of the supervisory working alliance on supervisee work satisfaction and work-related stress. Journal of Mental Health Counseling, 249-263.

Taylor, P. (1995). Graduate education and open learning: Anticipating a new order. In E. A. Buttery, (Eds.), An Overview of the elements that influence efficiency in graduate supervisory practice arrangements. International Journal of Educational Management, 19(1), 7-26.

Tancig, S. (2007). Postgraduate supervising model: A constructivistic, experiental and collaborative approach. Postgraduate Supervision: State of the Art and the Artist, (pp. 335-342). Stellenbosch, South Africa.

Wisker, G., Robinson, G., Trafford, V., Lilly, J., \& Warnes, M. (2003). Supporting postgraduate student learning through supervisory practices in Improving Student Learning: Theory Research and Scholarship. Rust, C, OCSLD: Oxford. 
Zuber-Skerritt, \& Roche, V. (2004). A constructivist model for evaluating postgraduate supervision: A case study. Quality Assurance in Education, 12(2), 82-93. http://dx.doi.org/10.1108/09684880410536459

\section{Copyrights}

Copyright for this article is retained by the author(s), with first publication rights granted to the journal.

This is an open-access article distributed under the terms and conditions of the Creative Commons Attribution license (http://creativecommons.org/licenses/by/3.0/). 